\title{
Sentido y aflicción en torno a la desnutrición infantil. Experiencia y narratividad entre los ch'orti' de Guatemala
}

\author{
Meaning and Affliction in Relation to Child Malnutrition. \\ Experience and Narrativity among the Ch'orti' of Guatemala
}

\author{
Lorenzo Mariano Juárez \\ Universidad de Extremadura, España
}

\section{RESUMEN}

Frente al discurso biomédico occidental, la construcción Ch'orti' de la desnutrición —la versión indígena del padecimiento- se ha tejido a través de representaciones colectivas que ahondan en "la falta de cuido" y la responsabilidad materna, y no tanto en la falta de alimentos. Este texto ofrece al lector un acercamiento a la etnografía de la desnutrición en esta región del oriente de Guatemala, a través del análisis de las relaciones que se establecen entre relatos y experiencias de madres que sufrieron la experiencia de la desnutrición de alguno de sus hijos. A pesar de los vigorosos intentos de "educación sanitaria y nutricional", las narrativas tienden a situar el discurso biomédico de los balances calóricos en una posición marginal. La etnografía propuesta intenta aquí ofrecer pistas para comprender esta cuestión, abordando la densidad de sentidos y significados de la desnutrición entendida como un asunto de déficits en balances simbólicos y políticos.

Palabras clave: Desnutrición; Ch'orti'; Narratividad; Experiencia; Guatemala.

\section{SUMMARY}

In opposition to the biomedical discourse, the Ch'orti' construction of malnutrition-the indigenous version of illness - has been shaped through representations that highlight "lack of care" and maternal responsibility rather than "lack of food." This paper explores the ethnography of malnutrition in this region of eastern Guatemala, through an analysis of the relationship between the narratives and experiences of mothers with children who have suffered from malnutrition. Despite energetic attempts at "health and nutrition education," the narratives tend to place the biomedical discourse of caloric balances in a marginal position. The ethnography proposed here seeks to provide clues to understanding this issue, tackling the density of its meaning and defining malnutrition as a matter of symbolic and political balances.

Key words: Malnutrition; Ch'orti'; Narrativity; Experience; Guatemala. 
Un par de días antes de la Nochebuena de 2015 conversaba con don Juan, un joven maya ch'orti' de apenas 24 años, cerca de su casa en la comunidad de "Suchiquer Oratorio". Había acudido aquella mañana acompañando a un equipo de la ONG Acción Contra el Hambre, observando el desarrollo de un proyecto donde se enseñaba a mujeres de la comunidad a cocinar comidas "con un balance nutricional adecuado", mezclando productos locales como ciertas verduras con masa de maíz e Incaparina. Desde hace más de una década, el paisaje de la cooperación y las prácticas desarrollistas envuelve la cotidianidad de esta región del oriente de Guatemala, donde las cifras se empeñan en retratar un lugar de pobreza, desigualdad y desnutrición, de manera acusada en la infancia: informes de diversas instituciones concuerdan que tres de cada cuatro niños está desnutrido ${ }^{1}$. La que fue conocida entonces como "hambruna de Jocotán" (López García 2002; 2008; Mariano Juárez 2008; 2011) se ha repetido de manera menos mediática cada año que la climatología o los precios del café no han acompañado. El patrón de las lluvias de 2014 ha vuelto a disparar todas las alarmas, reclamando una vez más la urgencia de la situación: o se actúa ${ }^{2}$, o habrá, una vez más, muertos por desnutrición.

En aquellas semanas de diciembre era usual contemplar la entrega gratuita de sacos de maíz o el desarrollo de diversos programas como el que me había llevado aquella mañana a conversar con aquel joven, huérfano de padre, sobre el asunto de la desnutrición, intentos de atajar una nueva crisis nutricional: "Ajá, bien dicen de esa desnutrición, que es por la comida, pero no es por eso, en veces no es por eso". Don Juan, tras confiarme con algo de sorna que "las recetas de la seño" no se volverían a hacer en la casa de ninguna de las mujeres, ahondaría luego explicando cómo el asunto de la desnutrición poco tenía que ver con la falta de comida. Aunque en su comunidad aún no había llegado la luz y la cosecha escaseaba, se encontraba comida suficiente para alimentar a los niños. Para mí, que he preguntado sobre estas cuestiones centenares de veces en la última década, el relato no resultaba sorpresivo. La retórica "tradicional" para explicar la presencia de "niños desnutridos" ${ }^{3}$ se asienta en un modelo explicativo donde se mezclan los "el niño dejó de comer" que refieren las madres y abren los historiales clínicos en los hospitales al "por falta de cuido", un denso universo cultural donde se construye una etiología del trastorno alejada de los balances calóricos y la falta de alimentos (Mariano Juárez 2011). El argumento de la falta de comidas se invalida sin dejar de asumir lo complicado que resulta la vida en la región: "uno es pobrecito, el maíz para ir pasando, la librita eso si no nos falta". La

\footnotetext{
${ }^{1}$ El índice de desarrollo humano de 0.391 , en la órbita de las regiones más pobres del planeta. El porcentaje de pobreza del departamento de Chiquimula es del $59.5 \%$ y el de la pobreza extrema del $27.7 \%$. En Jocotán, el municipio con la peor calidad de vida del país, ocho de cada diez personas son pobres (PNUD Informe Departamental de Desarrollo Humano, 2005. PNUD Guatemala)

2 Véase, por ejemplo, en los medios nacionales: http://elpais.com/elpais/2014/12/15/ planeta_futuro/1418651203_953231.html

3 "Desnutrición" y el universo semántico en el que se construye la versión indígena del disease es en la actualidad una mezcla de visiones tradicionales y el alcance "pedagógico" de discursos médicos y desarrollistas contemporáneos, conjugando de manera particular las distinciones "emic/ etic/tradicional/moderno/illness/disease». Una distinción que me ofreció de manera lúcida don Paulino, en Tunucó Abajo: "nosotros aquí decimos de al tiro, bien desnutrido que dicen ustedes por medio de estudio, desnutrido".
} 
retórica indígena de los «balances calóricos" responsabiliza de esta forma a las acciones u omisiones maternas y no a la falta de alimentos, una construcción etiológica anclada en un orden social y moral determinado ( ibid.). Si las definiciones occidentales contemporáneas de desnutrición tienen, también, su propia historia cultural, que arranca con el entonces moderno discurso científico y técnico expresado en tablas y calorías (Rowntree 1901; Edkins 2000), con el surgimiento de la Nutrición, y todas las investigaciones desarrolladas a lo largo del siglo XX, la historia cultural ch'orti' entremezcla las definiciones culturales del "hambre" (Mariano Juárez 2013), el espacio de los mitos, los roles de género o el contrato social de matrimonio, situando la etiología del trastorno en la retórica de la falta de cuido materno, que incluye prácticas durante la concepción, el embarazo y la lactancia (Mariano Juárez 2011, 2012).

Así se explican las causas de la desnutrición en conversaciones donde se cuelan las representaciones sociales de la desgracia. Pero, ¿qué sucede cuando el relato se construye desde la experiencia íntima de la desnutrición? ¿Cómo se construye la trama desde la posición de cuidadora, esto es, de las madres? ¿Las etiologías centradas en los "malcuidos" de las madres se imponen de igual forma a la escasez de cocinas o despensas en estas estrategias narrativas? ¿Cómo es negociada la culpa en las estrategias narrativas de madres con hijos aquejados de desnutrición infantil? Desde estos interrogantes de partida, me propuse el entrevistar a un grupo de madres ${ }^{4}$ para invitarlas a contar la experiencia de la enfermedad de sus hijos, las causas de la aparición de la misma, las acciones que llevaron a cabo para intentar poner remedio o los recuerdos que atesoraban del episodio. Construir el relato y definir la estrategia narrativa, que, en palabras de Byron Good "es una forma mediante la que la experiencia es representada y relatada, en la que los acontecimientos son presentados con un orden significativo y coherente, en la que las actividades y acontecimientos son descritos junto a experiencias asociadas a ellas y la significación que les aporta sentido para las personas afectadas" (2003: 255). Las pretensiones de este texto se centran entonces en adentrarse en el ámbito de significación desde lo íntimo de la experiencia fenomenológica a través de la construcción discursiva de la desnutrición infantil desde la óptica de cuidadores, intentando apuntar hacia ese intrincado y complejo proceso relacional entre relato, cultura y experiencia.

Un primer vistazo a estos relatos permite conocer cómo el elevado peso de la responsabilidad materna en esos discursos locales sobre las causas de la desnutrición se ve críticamente disminuido en los relatos de la experiencia personal, pero el espacio para las "moderas definiciones científicas" no se ensancha como les gustaría a los responsables de los programas de salud pública. Tal y como discutiré en profundidad más adelante, las tramas y "la elaboración" de las tramas de los episodios del padecimiento construyen o intentan enmarcar los acontecimientos y las acciones dentro de un marco de sentido y un orden moral diferente ; de alguna manera, la «elabora-

\footnotetext{
${ }^{4}$ Había planificado un total de 20 casos para la delimitación de entrevistas, con unos criterios de inclusión que requerían el ingreso de un hijo en el hospital, con diagnóstico de desnutrición, durante al menos un mes y poder acceder a los historiales clínicos de los pequeños. Al final, habida cuenta de las dificultades surgidas, sólo 14 casos fueron incluidos en el análisis que aquí presento.

${ }^{5}$ No es infrecuente que los relatos persigan construir los recuerdos de acuerdo a marcos de sentido determinados. Por ejemplo, el texto de Bandahuer-Schoffmann (1999: 118) sobre la me-
} 
ción de la trama" parece perseguir encuadrar los acontecimientos en una significación de la enfermedad como algo cotidiano, abierto a ese tipo de cosas que simplemente "Ocurren". Así, algunos relatos destacan la idea de que hay niños que llegan "con ganas de enfermarse", remite a un ideario colectivo que presupone de alguna manera la existencia de un destino previsto con anterioridad, algo usual entre los indígenas mayas ${ }^{6}$. Siguiendo con la línea del trabajo de Byron Good, los relatos persiguen un tipo de "subjuntivización" que se construye a través de la cotidianidad y la aleatoriedad de los episodios de enfermedad o la asunción de perspectivas diversas en la narración y no tanto a través de la responsabilización de madres y cuidadoras - el discurso indígena tradicional- o la explicación de comidas escasas o de un valor nutritivo suficiente - el discurso biomédico modernizador-.

La etnografía de estos relatos puede ofrecer pistas sobre el proceso de cambio cultural y el éxito de las prácticas capacitadoras del discurso biomédico y la cooperación. A modo de ejemplo, de todas las entrevistas propuestas para el análisis, sólo tres madres afirmaron con claridad ${ }^{7}$ que el diagnóstico de su hija fuese desnutrición, el resto, simplemente "se enfermaron". No deja de resultar significativo y curioso este dato, más si se tiene en cuenta que estos niños estuvieron ingresados por un tiempo de al menos un mes, algunos más de tres meses en una institución hospitalaria. Cada entrevistado componía su particular trama, imbricada en desencadenantes particulares y sumida en dinámicas familiares y sociales particulares. Sin embargo, al preguntar de forma genérica el por qué se desnutren los niños, la respuesta se acomodaba de forma literal al esquema propuesto como representación colectiva tradicional. La desnutrición de hijos o nietos "no parece ser" la misma que la de vecinos lejanos.

Las retóricas de las madres como responsables primeras del padecimiento de sus hijos dan paso a nuevos escenarios, narraciones que buscan dar cuenta de otros significados con los que dirimir la culpa materna y lidiar con los episodios de la desgracia. Las estrategias narrativas empleadas para narrar la experiencia de la desnutrición de un hijo se imbrican en - y en cierta forma construyen- el orden social y moral indígena. Y en este sentido, el poco éxito de la educación sanitaria se explica

moria de la población vienesa alude a ciertas ausencias como forma de resolver una contradicción: "no hablan del hambre en la posguerra en las entrevistas dedicadas a recoger sus historias de vida porque desean evitar hacer presente el conflicto de roles entre su papel de mujer proveedora y las posibilidades reales de cumplirlo (...) hablar de hambre pondría en entredicho esa imagen heroica de la hacendada desescombradora de ruinas". En este texto voy un poco más allá, pues los relatos se orientan hacia el presente y el futuro, no sólo en la dirección de construir los recuerdos.

${ }^{6}$ En la región, Mancho de Titicopote le relataría a Brent Metz: «Dios nos proporciona un espíritu que determina nuestras debilidades y nuestras fuerzas", o de forma más explícita en la manera ensayada por Pedro Súchite en Pelillo: "Dios establece el destino de todas las personas, unas están destinadas a trabajar con machete, otras a viajar, otras a dedicarse al comercio... incluso en el destino marcado por Dios se asigna qué idioma hablará cada quien" (1995: 197-198).

7 "Claridad" no equivale aquí a una asunción completa del modelo biomédico. Las causas últimas de la desnutrición o la rotundidad de las afirmaciones al respecto era variable. En oposición a otros tipos de "arquitectura" de las estrategias narrativas, aquí se aprecia cierta tendencia asimilacionista o sincrética con los postulados biomédicos, acciones y resultados del proceso de cambio a través de la medicalización de la región. Como discutiré en el texto, el número de entrevistas con este esquema, sin llegar a tomarse en un sentido representativo fidedigno, si parecen orientar hacia un proceso no muy logrado en la región. 
en el profundo carácter cultural de tales relatos, que delimita los límites de la narración.

\section{ARQUITECTURAS EN LAS ESTRATEGIAS NARRATIVAS. UN PRIMER ACERCAMIENTO}

Las narraciones ch'orti' sobre la experiencia de la desnutrición infantil, son, por supuesto, hondamente culturales. En ellas es posible rastrear redes de significación ligadas al simbolismo del sistema culinario, las relaciones de género asimétricas, el impacto del desarrollismo o las diversas encarnaciones de la memoria colectiva de la escasez, por ejemplo. Resultan densamente culturales porque los márgenes para los propósitos de la narración están marcados por la ideología y la cultura local, como también lo están las posibilidades de alternancia y cambio, lo que explica, al menos en parte, el lugar subalterno del discurso biomédico de la desnutrición.

El análisis que aquí propongo intenta poner de manifiesto la forma en que las estrategias narrativas se transforman en discursos performativos que juegan y conjugan tales órdenes de significación para dar un sentido alternativo a las representaciones colectivas tradicionales sobre el trastorno y los reparos para la aceptación de la educación sanitaria a la vez que constituyen un espacio inigualable para adentrarse en la etnografía de la región.

En relación con las narraciones sujetas a análisis, es posible delimitar tres grandes modelos o "arquitecturas" diferentes: aquí he distinguido entre las narraciones que "encarnan" el actual proceso de medicalización, una segunda abierta a "la pluralidad de perspectivas" y una última marcada por la inclusión de lo misterioso o las típicas narraciones culturales sobre el susto. Cada una de estas arquitecturas refiere pasajes diferentes sobre aspectos como el desencadenante del padecimiento, las causas del mismo, los procesos de búsqueda de atención, la estancia en el hospital o las visiones sobre las posibles recaídas. Sin embargo, lejos de ser simplemente modeladas en formas culturales, las estrategias narrativas formulan, en otras ocasiones, modos de construir la memoria de la experiencia y son empleadas como discursos para la acción y el cambio, narraciones cargadas de futuro en tramas que negocian con las hegemonías discursivas sobre el trastorno. En ellas es posible vislumbrar también rastros de los procesos de cambio, las alternancias en la ideología local. Veamos, antes que nada, la variabilidad de esas "arquitecturas narrativas".

\section{a) "DESNUTRICIÓN LE CAYÓ". "ENCARNACIONES" Y ESTRATEGIAS NARRATIVAS "GLOBALES"}

La primera de las entrevistas tuvo como protagonista a la mamá de Ingrid Marlene Carranza, doña Virgilia. No puso reparos en relatar lo que recordaba de la enfermedad de la niña, aunque desde un primer momento de la conversación se apreciaban sus ganas de girar el peso narrativo hacia la precariedad familiar, como si los episodios puntuales de enfermedad tuvieran sentido dentro de una trama de desgracia mucho más amplia. Al inquirir por los inicios del trastorno, al preguntar por los signos que le alertaron de la enfermedad de la pequeña, el diagnóstico resultó meridianamente claro: "desnutrición", además de tener "mal los pulmones". Como en la mayo- 
ría de relatos, se aprecian marcados esfuerzos por distinguir y delimitar los "qués" de los "por qués" en las narraciones sobre los acontecimientos. La pequeña presentaba diarrea desde varios días, y exhibía "ansia" propiciada por la pulmonía que la aquejaba, "todo eso me jalló el doctor y me entretuvo, un mes y medio estuve allí. Desde entonces, admite que cada vez que la niña cae con "ansia" o tos se dirige al centro de salud, tal y como acababa de hacer ocho días atrás, y una vez más había notado mejoría. Como todo antropólogo sabe, preguntar por las causas de la enfermedad es distinto a querer obtener las respuestas al "por qué a mí". Las asunciones sobre las causas de la enfermedad pueden buscar alternativas disímiles para responder a esta última pregunta, y quizás esto sea el punto de partida clave para estas reorganizaciones desde la experiencia. En cualquier caso desconoce las causas por las que sufrió su hija Ingrid, pero es capaz de especular con que se tratara de algún tipo de ausencia por parte de la pequeña. Admite su ignorancia, pero a la vez sitúa el origen del trastorno en el momento del embarazo: la niña vino así desde el nacimiento, porque ella apenas comía, pasaba todo el día así, con un traguito de café, admite con parsimonia, ni siquiera una librita pesaba. Doña Virgilia tiene otros dos hijos, los dos varones. El relato de sus dificultades económicas entremezcla la ausencia de su esposo en un trágico desenlace con las malas relaciones con su suegra, con la que no tiene relación a pesar de ser vecinos. Su esposo fue asesinado hace ya cuatro años, y el pequeño de los hijos tiene apenas diecisiete meses, pero su relato no aborda los motivos de las desavenencias. La intención o el sentido en la elaboración de la trama de su discurso parecen querer representar las dificultades de salir adelante sin ayudas; reconoce que siempre se halla la tortilla con el caldito de frijol, pero no sucede lo mismo con las "buenas cosas", la asunción tácita de la insuficiencia de la comida local y la simbología que sustenta a favor del esquema de los balances calóricos:

... cuando estaba mi marido hacía sus 10 tareitas, pero ahora, no, no puedo solo yo, va el hombre porque va a medir su tarea, está con su mozo, uno espera del hombre... cuatro años... el salió a andar ahí en una aldea que se llama Marimba, fue a la virgen dijo voy, vaya, salió; como a la una de la tarde salió, por la una de la tarde salió, ya como a las seis de la tarde llegaron, "está muerto", por las... pero no se sabe quién es, solamente Dios lo vio, nosotros no acusamos porque no lo vimos, pero ahí estaba que como ahorcao lo hicieron, de aquí le metieron la uña en el galillo y estaba bien morado el pecho, como que bien patadas le dieron... pero como no lo vimos iy qué quién es? Solamente Dios, como dice que es el que revisa el mundo, a toda hora, el sí que lo sabe (...) cuatro años tiene... vivo sola, solita estoy... vivo cerca de mi suegra, ahí está, no me da ayuda... porque se me estaba cayendo la casa y me dijeron que no me iban a ayudar, se me cae la casa... no me ayudaron, la gente aquí no me ayuda... la gente no ayuda... nadie me ayudaba, ique! Si solamente yo tenía que ver con la criatura es que allí ninguno ayuda, si uno tiene come y si no tiene que aguantar uno

— ¿y ahora cómo hace?

-Así... ahorita tengo un coche [cerdo] que así está el coche [señalándose a la altura de la rodilla], ya por lo menos ya tengo... es mi esperanza ya que lo voy a vender... la vez pasada cuando vendí un coche casi en 525 lo vendí... compré mis quintalitos de maíz, compré mi salita, y dejé, aparté 100 billetes, compre el vuelto otra vez, siempre que uno no me ve, compré el vuelto, ahí esta, ya está bonito otra vez.

La toma de la decisión de acudir a la consulta del médico también parece estar construida desde la reelaboración de los acontecimientos. Doña Virgilia admite sin 
pudor que el único remedio adecuado para tratar estos casos es acudir a los médicos, nada de remedios de monte, aunque en algún momento parece admitir que ella sí lo hizo. Esa claridad que exhibe al disertar sobre el itinerario más adecuado contrasta con las dificultades para tomar la decisión — dilatada por varias semanas- y que no se concretó hasta un momento en que la gravedad alertaba ya de un desenlace fatal. Aún así, admite que necesitó algún empujón, uno de esos proporcionados por ciertas "visitas", tan frecuentes en aquel tiempo. Doña Clarisa es una cooperante que le ayudó en aquellos días con los asuntos económicos, que cobran un protagonismo central en la elaboración de la trama, dando sentido a las decisiones y acontecimientos:

Ah, yo me fui con ella, ajá, porque yo vi que se iba a morir la niña, si no me hubiera ido allá al hospitalito se hubiera muerto la niña, y me fui con ella onde la vi que no pasaba nada de engordar, mire como está ahorita, bien desnutrida está todavía, aja, y me fui con ella. Cuando lo traje ya un poquito se miraba, se miraba mejor ya que cuando la llevé, que solo de trapos se miraba. Yo me fui, y también la seño Clarisa me vino a ver como en tres veces pa' que me iba y onde jallé mis centavos me fui... ella si me venía a visitar. Porque yo me iba con la niña... cuando estaba yo allá en el hospitalito me fue a visitar la seño Clarisa, me iba a visitar allá, cuando yo estaba en la casa, cuando no me había ido con la niña todavía, ella me vino a ver como en tres veces pa' ofrece irme pa'allá [para el Centro de Salud].

La versión de doña Virgilia parece perseguir ubicar al lector/oyente a un escenario de confianza en la atención médica, en certezas sobre lo adecuado de los tratamientos, pero también las dificultades que se hallan al pasar del pensamiento a la acción, habida cuenta de la escasez de recursos y el costo que parece implicar esta alternativa. En cualquier caso, de no haber acudido al auxilio de los doctores, la niña se hubiera muerto. Su estado era entonces dramático y "Sólo de trapos se miraba". El impacto desarrollista, ejemplificado esta vez en la figura de doña Clarisa, parece decantar la decisión, abriendo paso a nuevos escenarios. Los recuerdos de la estancia en el centro hospitalarios son densos, y la narración se organiza mediante las ganas de obtener el egreso, los intentos por adecuarse a las normas, frente a otros que salen "de escondidas" y el realce a la soledad en la que se manejó con la desgracia:

Pues si... allí del Centro de Salud salí afligido ya, ya... y llegué al hospitalito y me puse alegre, uno no aguantaba allá, siempre mi comida allá lo tenía... cuando llegué al Centro de Salud me afligí, me quedé triste. Me dijo la seño usted no se va a ir, va a dar la nota, no la vas a llevar a la nena de vuelta a la casa para que se muera... también en manos del doctor ella se siente feliz... eso es cierto, eso es cierto. Si uno deja morir a las criaturas 'porque uno de madre se siente por ahí, ellos primero Dios los ayudan otra vez... Había de otras aldeas, platicaba con ellos... me decían, yo me voy a ir me decían, eso no le decía yo, me aburro estar aquí me dijo, no, le dije, mejor esperemos, que cuando dice el doctor, aquí está tu salida pues tenemos que ir, pero durante no le decía no... como las personas que llegaban allá hay que platicar, porque sino uno se siente serio, no servimos así... hay que ser platicón con la gente, ahí nos poníamos platicando y cuando mi hermana me llegaba a visitar ... la gente que quería irse quizá era porque no quería ver alentados a sus hijos, allá es lo bueno que estén alentaditos... pero casi de dos días se van... saber por qué. Una vez llegó allí una de Jocotán de esos que ponen unas navas así; un día estuvo con la criatura, ahí se fue. Ah no, yo no, yo hice el tiempo. De escondida se fue, yo ni vimos cuando la otra señora se fue que horas. Siempre que no quieren el bien... saber, no quieren a sus hijos quizás... Hay gente que así sale de escondido, 
no mire pues que tal vez están privadas las criaturas y apenas hacen dos días y de ahí se van a chingar, cuando el doctor pregunta, pasa el listado de las criaturas... ya se fueron ya. No, pero nosotros no, yo nunca lo he llegado a hacer eso, porque se que no solo una vez la necesidad; la necesidad todas las veces la tiene uno, porque uno no se sabe con las criaturas que días pasan alentados y que días se enferman (...) nunca me llegaron a visitar allá, sólo mi hermana me llegaba a visitar, con una mi bolsa de agua y una mi tortilla, pero cuando iban en el pueblo, porque allí ninguno me llegaba a ver..., no les gusta visitar a los enfermos, no les gusta visitar a los enfermos, mi suegra ni una vez me vino a ver... mi mamá porque no puede, es ancianita ya, pero mi hermana me llegaba a ver, me decía en cuanto salía, ahorita no se, hasta que me diga el doctor le decía yo, ahorita no se, cuando me diga el doctor, tenés tu salida entonces yo te podré decir yo decía cuando me venía a visitar... y ahorita que mientras que sin el permiso del doctor no me voy a ir, eso es prohibido, eso es prohibido porque vaya con permiso de él uno con valor se viene con la criatura, y el otro enfermedad, ya tiene entrada otra vez, y si uno sale de escondido, ni porque lo mira a la criatura que está bien grave y ya no lo recibe.

En cualquier caso, el futuro está abierto a que lo mismo pueda volver a suceder, y de alguna manera eso parece marcar las actuaciones; no se sabe cuándo se va a necesitar los servicios médicos de nuevo, y aquí se reproduce una de esas ideas tan extendidas: no se sabe que días pasan alentadas las criaturas, que días enferman. Esa idea de apertura sobre el futuro parece encerrar proposiciones sobre lo no controlado, lo azaroso que resultan estas cuestiones de la desgracia; "no, no se sabe con las criaturas, no se sabe, de repente les cae una enfermedad más grave que tiene que ir uno", me cuenta mientras admite que con los otros dos niños también ha acudido al médico, por razones semejantes. En el hospital pueden dan buena comida, le dan alimentillo, pollo molido, papitas, molidas, papilla le llaman, y también verdura. Esa es "la buena" comida que allí les ofrecen, y con las inyecciones, la niña "se siente pollón entonces", en manos del doctor la niña se siente feliz. La madre continua explicando que esa comida no se halla en la comunidad, porque apenas llegan ayudas, salvo del Centro de Salud, desde donde en ese momento se está repartiendo arroz, aceite y harina. Y así les ocurrió a los otros dos hermanos continúa, y a uno de ellos "ni chicha tomó", se lamenta, sólo en la pacha creció el pobre, recreando de nuevo esa tristeza por no poder siquiera haberle ofrecido la lactancia materna.

No es esta la estructura narrativa más común en los relatos, y sólo 3 de las 13 entrevistas parecen amoldarse a este esquema, con un recorrido particular: el diagnóstico del padecimiento se acomoda bastante a los presupuestos del modelo biomédico y los discursos desarrollistas, ligando desnutrición con escasez alimentaria en los modos propuestos por el discurso global. De esta forma, estas narraciones tienden a elevar la situación de pobreza de la familia y lo exiguo de la economía doméstica. El trastorno de los pequeños es "desnutrición" ${ }^{8}$, un tipo de enfermedad con sus síntomas y signos, con sus causas delineadas por la retórica de la escasez y la pobreza. Y de alguna manera, es posible rastrear un proceso neocolonial de experiencias y moralidad, apuntando hacia las formas "buenas" de ser una madre: la que quiere a sus hijos, la que prioriza quedarse en el puesto de salud por encima de otras

\footnotetext{
${ }^{8}$ En una de las entrevistas esto no es tan claro, y las alternativas a otras posibilidades es mucho más marcada. Aun así, creo conveniente encuadrarla en este grupo, puesto que la presencia del resto de características es más que evidente.
} 
cuestiones (Mariano Juárez 2012). Por supuesto, el paso de las "causas generales" al "por qué a mi hijo" conlleva una búsqueda de etiologías que exceden esos universos causales, y estas retóricas también abrigan alternativas en explicaciones y tramas diversas. La "encarnación" de esos nuevos modos se expresa también en el hecho que la búsqueda de soluciones - pasadas y futuras- parece delimitada al ámbito del itinerario biomédico, y las estrategias narrativas inciden en la "exclusividad" de médicos y hospitales para tratar el trastorno. De esta forma, los acontecimientos son narrados a través de fracasos en la búsqueda de remedios en la comunidad, o bien, que es lo más normal, reorganizados sobre la futilidad de tales prácticas y la necesidad más que evidente de acudir al médico.

\section{b) NARRATIVAS DIVERSAS}

La estructura más frecuente en torno a la que se organizan la mayor parte de las estrategias narrativas (ocho de trece) sigue un patrón diferente desde el propio proceso de definición o categorización del episodio de enfermedad. Ante la pregunta que incita a describir el inicio de los acontecimientos, "que fue lo que le pasó", los diagnósticos de los cuidadores abundan en episodios puntuales de diarreas, revolturas, asientos, pérdidas de apetitos o enfermedades que, simplemente, "les caen" a las criaturas. La construcción y narración de estas tramas apenas involucran a la desnutrición, ni siquiera para rememorar los comentarios de los médicos en el centro de recuperación nutricional, quienes nada dijeron, o nada se recuerda que dijeran. Frente a la densidad de la narración sobre los consejos, las experiencias en hospitales o centros de salud, los comentarios moralistas del esquema anterior, esta fase de la experiencia de la enfermedad es verdaderamente exigua en esta "arquitectura narrativa", en donde apenas se dedica tiempo. Cuando lo hacen (y en alguna ocasión esto es debido a imposiciones del discurso por parte del etnógrafo), los comentarios sobre la desnutrición se reducen a un mero reflejo sintomático de la existencia de un trastorno, una traducción en síntoma de la delgadez de los cuerpos. La desnutrición como categoría biomédica desempeña, a duras penas, el papel de un actor de reparto?

El relato de doña Lucía Pérez Ramírez sobre la enfermedad que aquejó a su hijo Melvin Munesh, en julio del 2004, podría servir de ejemplo de la «arquitectura narrativa" más usual. Doña Lucía relataría en su casa de Ingenio los acontecimientos que se sucedieron aquellos días; recordaba con meridiana nitidez que acababa de dar a luz a una de las hermana de Melvin cuando fue necesario ingresarlo, habida cuenta de la gravedad de la situación. Doña Lucía describía la situación del pequeño como irreversible, se había hecho todo lo posible, pero el destino parecía jugar con cartas marcadas. A pesar de los esfuerzos, la suerte estaba echada, todo parecía una mera cuestión de tiempo. Melvin se moría. Se había abandonado toda esperanza:

\footnotetext{
${ }^{9}$ Como me contaría don Demetrio, un joven padre con su hijo ingresado en el Bethania por desnutrición, sobre el diagnóstico que le habían ofrecido los doctores: "Pues el doctor me dijo que más o menos estaba desnutrida porque tenía diarrea, pero que ella tenía enfermedad directa de desnutrición me dijo no tenía, sólo porque estaba más enferma de diarrea, ¿verdad?, y sólo por eso estaba bien desnutrida".
} 
La diarrea, revoltura, cuando lo llevaron ya no tenía cuanta de que él iba a vivir, por eso lo llevaron, Acción [Acción contra el Hambre] es la que lo llevó... no tenía cuenta... me dijeron sólo para ocho días estaba, y yo como estaba tierna hice el cumplentillo de irme con él... Quedó de al tiro, quedó asinita (señala con el pulgar y el índice) y una vez se pandió la nuca, ni se podía sentar... eso fue de la diarrea, porque desde chiquito lo despeché también para tener a la otra... Fue en julio, a él lo llevaron el 25 de julio. Lo llevó Arnaldo Vázquez, era el que venía allí de Acción cuando estuvieron dando alimentos ahí en la escuela... yo pensaba que ya no iba a vivir, cuando llegó de al tiro de la mano de él, se desmayó de camino. Cuando estaba enfermo le di remedio como uno de monte, remedio de monte se puede dar, le di el benadillo con el albajaca se daba... No se alentó y entonces ingresó él. Acción hizo cumple de pagar. Estuvo mes y 20 días. Él iba a verlo, el papá iba a verlo cada tres días. Yo llegué pero las enfermeras que estaban allá me dijeron que podía agarrar una hemorrage grande que yo estaba de diez días (desde el parto) cuando llegué allá a ver... y no volví... cuando el vino bien gordito el vino... vino el 12 de septiembre lo trajeron...

La narración de doña Lucía está abierta a las contradicciones, y en algún otro momento, por ejemplo, rehace la historia con un relato donde es ella la que acompaña siempre al papá en las visitas cada tres días ${ }^{10}$ y en otras ocasiones se equivocan las fechas y los tiempos. La diarrea - "Ocho días de diarrea y se fue hinchando entonces" - como elemento desencadenante alterna en otras ocasiones con el hecho manifiesto que ella dejó de ofrecer el pecho a Melvin en el momento que se dio cuenta del avance del embarazo y en otra ocasión apunta a cierto impericia sobre "los juegos de los pequeños". La vida cotidiana en esta región se mezcla en las narraciones, ofreciendo retazos de las decisiones, de las expectativas. Al final se acepta el desconocimiento que mezcla el desconsuelo con un así son las cosas: "yo no se por qué será que le cayó esa hinchazón mi hijito rey".

Como en la mayoría de historias enmarcadas en este modelo, se aprecia que frente a lo exiguo de lo narrado en torno a la experiencia con el sistema médico - advertencias, regañinas, consejos de salud, conversaciones sobre la evolución, diagnósticos... - que tienden a recluirse en las periferias del relato, los procesos de auto-atención y autocuidado son densamente narrados. Es cierto que el tono de fracaso es, en ocasiones, evidente, pero estos "remedios de monte" no son, desde luego, nada contraproducentes. La densidad narrativa en este apartado parece compensar la delgadez de la experiencia biomédica. Familiares y vecinos parecen opinar sobre la evolución y tratamientos posibles, y el recurso al sistema médico parece marginado a las postrimerías. Los recursos propuestos por el desarrollismo parecen en ocasiones abocar hacia el empeoramiento. Hay veces, me cuenta con ese particular tono que mezcla la confidencia con lo evidente, que simplemente "los niños no quieren creer",

${ }^{10}$ Pareciera como si de esta forma se construyesen los acontecimientos en busca de una actitud más agencial de los padres, en contra de ese relato sin apenas participación donde Melvin fue arrastrado por el cooperante de la ONG. Es difícil contrastar la información denotativa de este discurso, pero la pongo en cuestión, más allá de una actitud epistemológica de recelo. Las visitas al hospitalito son infrecuentes, una a la semana en el mejor de los casos, generalmente en domingo para hacer coincidir con el paseo al mercado. Las precarias economías intentan optimizar recursos de esta forma, y es muy usual que las visitas se produzcan cada quince días. Además, las propias enfermeras del dispensario Bethania favorecen con sus consejos una estancia del pequeño con visitas muy espaciadas, una práctica discursiva centrada en evitar los llantos de los pequeños con las despedidas maternas. 
dotando con las pausas escogidas ese aire de verdad revelada que parece indicar que a pesar del daño, así son las cosas:

Él estaba pesando solo cada quince días, estaban ahí y le daban [maíz] amarillo y le daban... entre más le daban más se ponía... por eso... en la pesa eso me daban harina amarilla... pero más pior lo ponían. Lo dejó de beber hasta que lo llevaron... remedio fue que le di, me dieron y le echaron... le di suero pero no quiso creer. También le dimos remedios de monte, este, nosotros decimos aquí es bueno para saconais, es bueno para la diarrea, albuajaca benadillo de tres puntas, eso es cocido, así no más fresco, no se alentó, no pudo ser... hay veces que creen y hay veces que no, como hay veces que la enfermedad aparece...

Los fragmentos de la historia que abarcan las estrecheces económicas no tienen un sentido central en las causas de la enfermedad propuestas en los relatos, y en el caso de doña Lucía, parecen converger con el hecho de su reciente parto para intentar justificar la escasez de sus visitas. Los centro de salud, los hospitales o el dispensario Bethania, a diferencia del modelo anterior, no son los destinos "evidentes" para el trastorno, sino más bien un recurso final al que adherirse cuando los anteriores fracasan. De esta forma, la confianza en que los niños se curen no es tan absoluta como en los relatos anteriores. A fin de cuentas, eso acontece con más frecuencia de la deseable en la zona, advierte en ese tono tan pedagógico. Hay niños que simplemente no quieren creer, retomando esas ideas sobre el destino de cada cual, las fortalezas y las debilidades de cada cuerpo. Los mundos locales retoman aquí el protagonismo del sentido y la experiencia narrada. Doña Lucía pensaba claramente que Melvin fallecería en pocos días, y a veces hace notar como algunos (en el relato parece intuirse que incluye aquí a su esposo) le advertían que lo mejor era esperar el desenlace en la casa. La confianza en el modelo alopático es menor, lo que da cabida a otro tipo de prácticas, sancionadas en los primeros relatos. Doña Lucía, en un tono mucho más confuso y enmarañado, confiesa que acabaron "Sacando" al niño del centro hospitalario, optando, según esta versión, por un tratamiento ambulatorio; el recelo y las lagunas del relato parecen indicar que es consciente que es una práctica tal vez no entendida por el oyente:

le decía yo que iba a ir a verlo, porque como a él sólo le ponían los remedios nosotros los traibamos y nos volvimos a ir con él, así fue, no le puedo mentir... y si porque como lo traiga era porque lloraba mucho... (lo sacaron) el no decía nada, pero como el niño mucho llora no lo dejamos, lo traimos pero estamos siguiendo con él hasta que se le vio.

Ante la ausencia manifiesta de la desnutrición en el discurso de la madre, al final de la conversación pregunto de forma impositiva sobre el diagnóstico que aparece en el historial médico del pequeño Melvin; ¿le dijeron que era desnutrición? La respuesta se acomoda desde luego mucho más a las representaciones colectivas tradicionales, y se aprecia cierta resistencia a una respuesta afirmativa, cómo si de esa forma se esquivase el estigma que parece construirse ante ese diagnóstico ${ }^{11}$ :

${ }^{11}$ Las categorías como "estigma" y la propia retórica de la culpa materna son difíciles de encuadrar en un contexto social e histórico determinado sin implicar los efectos de los discursos biomédicos y desarrollistas. En cualquier caso, este diálogo parece mostrar esas formas de resistencia a ciertos significados implícitos del discurso global: vuelve a ser una forma de conjurar la culpa individual, esta vez en diarreas que caen. 
Es des... desnutrición, tenía eso si pero... ¿̇abe por qué queda desnutrido el niño? caen diarrea y es en ese entro en la criatura desnutrido, porque si le cae a una persona grande, pero si le cae bastante ahora, no sostiene eso, es el mal que le cae a uno, y a saber porque será, no sabemos porque le cae...

De esta manera se articulan la mayor parte de las estrategias narrativas sobre la experiencia de la desnutrición infantil en la región, apegadas al contexto cultural, realzando los modos locales, pero sin renunciar a buscar otros significados presentes en la narración más allá de las representaciones colectivas sobre la culpa materna, tal y como discutiré a continuación, explicitando esas tensiones entre tradición y modernidad a través de los relatos de la experiencia del padecimiento. La explicación biomédica, pesar de la relación establecida durante las semanas de ingreso, es marginal. Pero hay una tercera "arquitectura" en la que puede enmarcarse estas particulares narraciones.

\section{c) El SUSTO Y LO MISTERIOSO EN LA CONFIGURACIÓN DE LA TRAMA}

Por último, dos de los casos se cobijaban en una trama marcada por las retóricas y el universo semántico tradicional del susto, y en cierta medida, en un reclamo a lo misterioso, que en el trabajo de Good es una de las fuentes de "subjuntivización" de los relatos de sus informantes. En el caso de Soraida Méndez, la narración estaba articulada de forma central entre el inicio y el final del episodio de enfermedad, mientras los acontecimientos intermedios eran relatados con superficialidad y prisas. En esta ocasión, el peso del relato recayó sobre el papá, quien dominaba el discurso, interrumpiendo de malos modos los intentos de su esposa por unirse en la narración. Ese día me acompañaba una de las guardianes de salud de la comunidad, quien me llevó a la casa, y facilitó el encuentro. Frente a la impulsividad vetada de la madre, el papá parecía mostrar un pose marcada por el desdén, un tono condescendiente cercano a la altanería; desde la hamaca donde hablaba parecía mostrar con el cuerpo cierto desaire por tener que contar algo tal vez evidente, algo que había quedado en el pasado ${ }^{12}$. Desde luego, a diferencia de la gran mayoría de entrevistas, en este caso la enfermedad no se encontraba en la mitad de la historia, sino que daba cuenta de un fatal desenlace. Las causas del mismo se alternan una y otra vez con el origen del trastorno:

... ella primero se cayó allá arriba y en eso fue que se espantó... se le fue subiendo [el hinchazón] los pies... después egresó y después no fue tanto, ahí se le subió en todo el cuerpo... eso tardó como veinte días quizás... si, desde que se vino de Bethania ahí le volvió a caer de vuelta — al año apunta la mamá- al año fue que le cayó, de ahí que caminó entonces ${ }^{13} \ldots$ no sé cómo será que fue que le volvería a caer...

- por tres veces — lo apunta también la mamá, que sigue en segundo plano la conversación, algo temerosa-, la íbamos a llevar de vuelta pero como ella no... no tuvimos tiempo... el mes 14 de septiembre fue que se desfalleció (...)

\footnotetext{
${ }^{12}$ Sin duda, el desenlace fatal del caso media en estas representaciones mucho más cerradas que construyen la trama, mucho menos abierta a significados potencialmente presentes.

13 "Caminó entonces" es una de las formas de expresar el significado que se otorga en la región a la muerte, caminar a otro traspatio, dejar el puesto.
} 
Ella fue porque se cayó allí donde está el tubo y ahí fue que se espantó... le dimos remedio y no, y no creía na, no se le bajaba na...

Son los dos hechos centrales en toda la narración: el inicio accidentado del padecimiento, con una caída y el posterior "susto", y el fatal desenlace. A pesar de los intentos, la niña "no quiso creer", entronando ese discurso tan extendido que parece distinguir unos cuerpos de otros. El papá explica con detalle que la pequeña le tenía miedo, porque él la regañaba. En la huida, la niña se cayó, el acontecimiento que supuso el inicio del daño, en una perspectiva aparentemente menos misteriosa:

Sí, desde que se cayó hay que saber porque será que ese de otro fue, de otro que lo mandaron y como me tiene miedo, me tenía miedo y por salir de huida ahí fue que se cayó y se lisió en el tobillo, del calcañar, se lisió y ya cuando vine yo del pueblo y ya estaba lisiado entonces, se quedó hinchado de la lisiadura...

El relato aborda los detalles del itinerario terapéutico, los reclamos a lo costoso del mismo. Las sospechas de que la niña se hubiese asustado propiciaron la búsqueda de remedios en la comunidad. Los esfuerzos resultarían infructuosos, a pesar de la reiteración de los intentos, las consultas con los especialistas locales. La enfermedad de la niña avanza, y un día alguien se acerca a la casa, en una parte del relato que se vuelve confusa y ciertas sugerencias para el internamiento de la pequeña parecen mezclarse con un tono más impositivo. La niña estaría entonces un tiempo en el Bethania, donde mejoró de la enfermedad. En ningún momento del relato, esta parte de la experiencia es narrada con detalles. Apenas se mencionan los consejos de los médicos, los recuerdos de las conversaciones mantenidas, poco más allá del pago por los servicios prestados, de esa idea constante por poner de manifiesto la voluntad de la niña. Ninguno de los tres hermanos se había enfermado nunca de esa manera, una tendencia en responsabilizar a Soraida del desenlace; el relato persigue de esta forma, lo mismo que los anteriores: ubicar la responsabilidad y la culpa en tierra extraña a las acciones de los padres:

Ah sí, utilizamos bastantes remedios de monte, pero no, no cree... íbamos a buscar remedio en otras partes a ver como salía... decían que era espanto lo que tenía y así le decían remedio y no cree... lo del espanto me lo dijo un médico que vimos aquí... de aquí que... de la comunidad, se llama Juan Suchiteque... Pero no hubo remedio ni nada... a ella le salió unas grandes llagas en las canillas... Saber de qué sería... de la hinchazón quizás, de la hinchazón quizá se le hizo llaga (...) Allí soplao le hicieron, ah, soplao le dicen... yo estaba, curarlo así... pero aquello no... tres veces fue que llegamos a su casa... le pagamos setenta y cinco, setenta y cinco pesos le pagamos y no se alentó... eso es caro, si es caro. Solo le soplaba y él decía que se alienta, me decía que se alienta pero mas rebajamos más pior se ponía, ajá... Creo que él me dijo, pues el decía que se iba a alentar la niña pero ¿cómo?, como tres veces que me fui el no le hizo nada ya no... veinticinco quetzales cada vez... cuando vio a la niña la primera vez el dijo que se iba a alentar, pero como salió que espanto era lo que tenía... saber cómo se sabe que es, como es él el que sabe, sólo estaba que no quería recuperar, la tres veces le hacía la misma cosa, pero como estaba muy propasado de hinchado... una señorita que vino de allá [¿̨idel pueblo?], allí vinieron en piecito andaban y le contaron que había una que estaba enferma, se la vinieron a traer y se la llevaron... era bueno que se la llevaran... y luego cuando vine fuimos nosotros a dejarla, estaban todavía esperándome a mí ella, es que yo estaba todavía en... cuatro de la tarde fue que llegamos... nos fuimos en carro, en carro... Estuvo como- ¿cuántos días? — un mes apunta la madre - un mes. Sí fuimos a verla y paga- 
mos... ajá... este... cien billetes por todo... Ajá... ella se puso mala de vuelta... más veces y la íbamos a llevar de vuelta, pero, pero como ella ahí no quiso ir de vuelta ya... no quería irse ya y como ella pensó que se iba a alentar más... se hinchó y caminó entonces.

La historia comienza a cerrarse con el alta de Soraida del centro hospitalario, recordada de forma borrosa o contradictoria, en un relato que omite los detalles de la estancia. El papá relata unos acontecimientos algo "enrevesados": un día se acercó a verla y el viaje resultó "por gusto"; la mamá había ido a recogerla, pero la madre no recordaba o no parecía recordar sobre ese día. La idea de los dos es que la recaída siguiente que desencadenó en el fallecimiento podía haber sido tratada en el dispensario, pero la pequeña se esforzó en negar tal posibilidad. La pequeña se empecinó en la negativa en acudir al puesto de salud, con desenlace fatal: "No, no iba a morir pero como a ella es que le cayó macizo, por eso es que se murió entonces... se murió por... el hinchazón, ya no quiso que se la llevara entonces... El mero 14 fue que falleció... ella tenía siete años". La pregunta del etnógrafo parece mostrar el desconcierto ante el desenlace narrado, la "autoridad" de la decisión de la pequeña, con apenas siete años. Cierta incredulidad que no parece alterar el discurrir del relato:

Allí en el Bethania si se alentaba pues, se alentaba, pues si la hubiera llevado desde que empezó a hincharse de vuelta se hubiera alentado, ahí estuviera la patoja, pero como ella ya no quería irse también...

- ¿Por qué no la obligaron a irse

—Bien, le dije, no dijo, ya estoy alentada dijo ella, por eso y así fue que se hinchó más y se murió.

Tal vez el desenlace trágico esté detrás de una trama tan cerrada, abierta a pocas alternativas, en cierta manera vetada a la especulación. Así fueron las cosas, así de sencillo y de simple, parece que muestran los gestos del padre, mientras intercala en la narración, sin ser algo central para el relato, lo apurado de aquel tiempo, alternando el paso del huracán Mitch con otras penurias y escaseces. Como decía, sólo otra narración más se articula en torno al susto o la aparición de lo misterioso como fuente de lo desconocido. Y los dos casos parecen marcar distancias con los nuevos modos, formas quizás de resistencia o afirmaciones de la tradición, o meros rechazos a los postulados biomédicos. Dejo aquí un esquema de estas tres estrategias narrativas: 


\begin{tabular}{|c|c|c|c|}
\hline & $\begin{array}{c}\text { "Medicalizado" } \\
(3 / 13)\end{array}$ & $\begin{array}{l}\text { Pluralidad narrativas } \\
\qquad(8 / 13)\end{array}$ & $\begin{array}{c}\text { Misterioso/Susto } \\
\text { (2/13) }\end{array}$ \\
\hline Desencadenante & $\begin{array}{l}\text { Desnutrición; } \\
\text { No alimentos } \\
\text { "buenos". } \\
\text { "Desnutrición como } \\
\text { enfermedad" }\end{array}$ & $\begin{array}{c}\text { Cae enfermedad } \\
\text { Diarrea, solturas, asientos. } \\
\text { "se hinchó", } \\
\text { desnutrición como síntoma } \\
\text { corporal }\end{array}$ & $\begin{array}{c}\text { Caída, miedo a la } \\
\text { pesa... } \\
\text { Desnutrición: } \\
\text { Residual, Expresión de } \\
\text { delgadez }\end{array}$ \\
\hline Causas & $\begin{array}{l}\text { No comer bien; } \\
\text { Indeterminadas. }\end{array}$ & $\begin{array}{l}\text { Desconocida. } \\
\text { Así ocurre. } \\
\text { Especulación }\end{array}$ & Susto. \\
\hline $\begin{array}{l}\text { Búsqueda } \\
\text { atención. } \\
\text { Auto-atención } \\
\text { Comunidad }\end{array}$ & $\begin{array}{c}\text { Sólo médico } \\
\text { R. locales } \\
\text { "contraproducentes" }\end{array}$ & $\begin{array}{c}\text { Densidad narrativa } \\
\text { Comunidad; } \\
\text { Remedios locales inefectivos } \\
\text { en ese caso. } \\
\text { Grave: atención Médica }\end{array}$ & $\begin{array}{c}\text { Comunidad; } \\
\text { Especialista Local } \\
\text { Grave: Médicos cómo } \\
\text { obligación; Negativas } \\
\text { y/o } \\
\text { Resistencias }\end{array}$ \\
\hline $\begin{array}{l}\text { Estancia } \\
\text { Hospital. }\end{array}$ & $\begin{array}{c}\text { Buena; Densa Es el } \\
\text { lugar donde curan, } \\
\text { hay que } \\
\text { comportarse }\end{array}$ & $\begin{array}{l}\text { Relativa; zona de conflicto. } \\
\text { Zonas marginales del relato }\end{array}$ & No importante \\
\hline Recaídas/futuro. & Muy posible; & $\begin{array}{c}\text { "Saber". } \\
\text { Incertidumbre al respecto }\end{array}$ & $\begin{array}{c}\text { Especulaciones } \\
\text { vetadas. }\end{array}$ \\
\hline Conflictos & $\begin{array}{c}\text { Económicos. } \\
\text { Familiares; } \\
\text { Soledad. }\end{array}$ & $\begin{array}{c}\text { Conflictos Familiares } \\
\text { Abuela/madre. }\end{array}$ & Conflictos con esposo. \\
\hline
\end{tabular}

FIGURA 1.-Esquema de "arquitecturas base" de las estrategias narrativas.

\section{LA TRAMA Y LA ELABORACIÓN DE LA TRAMA. CULPAS INDIVIDUALES, ABSOLU- CIONES NARRATIVAS}

El mencionado trabajo de Good centrado en las premisas que constituyen la relación entre enfermedad y la experiencia y las prácticas interpretativas se auxilia en la teoría narrativa de la "respuesta del lector", esencialmente en las aportaciones de Iser (1978). Alejada de anteriores posicionamientos estructuralistas, el trabajo de esta au- 
tor se centra en las características temporales e intersubjetivas de cualquier narrativa, prestando atención — citando a Ricoeur-, a la "fenomenología del acto de seguir una historia" (1981: 277, cit. en Good 2003: 261). De acuerdo con estas premisas, la narración dista de ser exclusivamente lo que está presente en un texto, sino que incluye a todo lo que se construye en la interacción entre texto y público o lector; la apropiación por parte del lector es un acto de compromiso activo donde el mensaje se incorpora componiéndolo. Retomando a Iser (1978: 22-23), "la labor del intérprete debería ser dilucidar los significados potenciales de un texto", "dilucidar el proceso de producción de significado". En su trabajo sobre las narraciones de la experiencia de pacientes aquejados de epilepsia en Turquía, Good toma prestados tres conceptos analíticos a partir de esta literatura: la "elaboración de la trama de la enfermedad", las características "subjuntivizadoras" y "el lugar del sufrimiento" en la narración. En su trabajo apunta a la importancia de esta teoría para emprender el análisis de esas historias que tienen más cercanía al "texto virtual" que al texto "real" ". Veamos las posibilidades del primero de estos conceptos.

La teoría narrativa distingue con claridad dos aspectos sobre la trama: como estructura subyacente del relato y la "elaboración de la trama", en relación con la participación activa del oyente para construir y dotar de sentido a la historia. Aparentemente, las tres estructuras o arquitecturas que cimientan cierto orden en la narración de los acontecimientos parecen ofrecer alternativas a las asunciones sociales compartidas por lo indígenas ch'orti' sobre el hambre y la desnutrición: los sesgos de género, las culpas, la retórica de "malas madres", los aspectos simbólicos del maíz... todo ello parece ciertamente ausente en la construcción desde la experiencia cercana de estos relatos. Sin embargo, en mi opinión, está verdaderamente presente en ese desarrollo, en los procesos intersubjetivos que median entre las construcciones de tramas "virtuales" por parte del narrador y la acción de apropiación y negociación de nuevas tramas "virtuales" ${ }^{15}$ por el lector. El sugerente análisis de Good adolece, en mi opinión, de obviar o menospreciar la carga evidente del peso de las tradiciones presentes en ese intercambio dialogal de escrituras y lecturas, elemento central que interfiere en los procesos creativos de tales tramas virtuales ${ }^{16}$. La retórica de la desnutrición como la expresión de las asimetrías de género a través de la culpa materna (Mariano Juárez 2011) y abierta a los actuales e incesantes procesos de cambio están presentes — con esa irónica presencia construida a través de la negación y la búsqueda de relatos alternativos-, en la construcción de la trama. Citando a Peter Brooks (1984: 11), "la trama, tal y cómo yo la concibo es el propósito e intención de significado. Podemos concebir la trama como la lógica o acaso como la sintaxis de un cierto

\footnotetext{
${ }^{14}$ Good toma prestada la distinción propuesta por Bruner (1986) para delimitar cada uno de estos textos.

${ }^{15}$ El trabajo de Good parece delimitar esta construcción del texto virtual al proceso intersubjetivo entre narración y lector, participando con su imaginación (ibid:: 265). En mi opinión, todos los relatos son construidos "Virtualmente" — siguiendo con la distinción de Bruner, desde la narración del autor - en un proceso de elaboración donde median las representaciones culturales, hegemonías y subalternidades y por supuesto, ese proceso dialogal y activo entre autor y lector.

${ }^{16}$ Las manidas discusiones de la disciplina sobre relato, experiencia, tradiciones diversas, interpretación y representación pueden tener aquí un punto de partida interesante para enriquecer los debates.
} 
tipo de discurso, un discurso que desarrolla sus proposiciones sólo a través de la progresión de secuencias temporales". Desde mi punto de vista, el "propósito e intención de significado" de las tramas de la experiencia de la desnutrición, con los desarrollos, esquemas o estructuras señaladas, es compartido: negociar las sanciones retóricas morales sobre el trastorno, traducidas en culpas individuales en la experiencia en "absoluciones narrativas" a través de los relatos sobre la experiencia de la enfermedad; y en segundo lugar, tal vez atenuar los estragos de la desgracia, atemperar los modos del sufrimiento en culturales narraciones de la vulnerabilidad.

La escasa importancia del discurso biomédico de balances calóricos en las definiciones culturales indígenas para la desnutrición se aprecian no sólo en su limitada presencia narrativa, sino en la ausencia en los procesos de subjuntivización de los relatos. Esto es así, intuyo, porque el relato biomédico de los balances calóricos pone en cuestión la versión indígena del hambre y las valoraciones sobre la competencia masculina en el contrato social del matrimonio (Mariano Juárez 2013): al situar la etiología en la falta de comida adecuada, se pone en cuestión la responsabilidad masculina, una versión que confronta profundamente las representaciones "femeninas" de la etiología de la desnutrición. "Subjuntivar es... moverse entre distintas posibilidades humanas en lugar de certezas asentadas", pero las posibilidades ofrecidas se enmarcan dentro de la plasticidad que ofrece la cultura y sus límites. La frase es de Bruner (1986: 26) y Good la toma prestada para refrendar las tesis de este autor en torno a cómo el discurso narrativo consigue la eficacia "reclutando la imaginación del lector" (ibid: 25) en su desarrollo analítico de las estrategias subjuntivizadoras en los relatos de enfermedad (2003: 276-285). Entre estas características subjuntivizadoras, las narraciones se abren a diferentes versiones, a múltiples perspectivas, a episodios seleccionados en órdenes no siempre cronológicos, expresiones de ese potencial para múltiples lecturas. Incluso las narraciones aferradas a los postulados biomédicos, daban rienda suelta a otras posibilidades. La mamá de Ana María relata la historia del ingreso de la pequeña motivado por diversas causas a medida que avanza el relato. Cuenta como el hermano mayor, Abraham, también estaba enfermo, pero "no muy grave, desnutrido estaba". La enfermedad de Ana María resultó ser más compleja, y el agravamiento de la situación determinaría que el ingreso en el dispensario a causa de la hinchazón que presentaba fuera ineludible; la causa original era la aparición de la diarrea. El internamiento se dilataría por algo más de un mes y medio, pero en otra parte, la narración encuentra en un dolor de estómago sin causa aparente el origen. Su hermano apenas mostraba los estragos de una enfermedad sufrida de pequeño, sólo desnutrición tenía, y su estancia no llegó a las tres semanas:

De aquella vez no mire que como que cuando le empezó como quemaos los pies, aquí ve, como si alguien lo había sentado en el fuego, le empezó como granazón en el pie y de ahí le fue hinchando hasta que se hinchó — como llaga — y en eso vinieron los guardianes y dijeron que lo iban a llevar, lo llevaron entonces para Bethania, llevaron a él y llevaron el otro porque los dos estaban así... enfermos... esta es la que estaba más grande (...) El doctor me dijo que enfermedad tenía en las tripas, si, tal vez que tenía lombrices, Ana María. Ahora, el que quizá no era Abraham, decían que él desnutrido nada más estaba, que fue de una gran enfermedad que él tuvo de más chiquito, yo aquí no más lo curé, tanto darle medicinas así compradas, y se le calmó, y a los pocos días volvió a caer, entonces y así con medicinas... cuando vinieron los guardianes que se le iban a llevar entonces ya él no tenía diarrea ni dolor, solo que él estaba bien de al tiro, él estaba bien de al tiro cuando yo lo llevé, pero él recuperó. 
Al preguntarle de forma general el porqué de las causas de la desnutrición en los pequeños, la mamá de Ana María adopta algunos de los escenarios tradicionales sobre la mala atención, la necesidad de aseo e higiene. Pero en su caso, ella tiene otras cuatro hijos más, resaltando que los demás no se han enfermado, ofertando otra idea muy consensuada que hay niños que tienden a enfermarse sin razón (y "culpa") evidente. El relato sobre la estancia en el hospital o los consejos de los médicos, se centra en la necesidad de cuidar a los pequeños, de alimentarles a la hora, de asearlos con atención, y la explicación de los doctores para el suceso: ella había despechado al pequeño. Los reclamos al desconocimiento de las causas para aquello y un destete precoz dan paso a una nueva explicación: Los pequeños son "pepes", huérfanos de su padre, y ella sólo tiene a su madre para ayudarle con el proceso. La imposibilidad para comprar alimentos y medicinas aparece también en el relato, contribuyendo al desarrollo de una enfermedad preexistente:

... porque ya está así uno... nosotros en el monte no hallamos que... alimento darle a las criaturas, y además como ellos son pepe, ellos son pepe, está muerto el papá de ellos, sí, ahí es donde yo no hallo cosas para darles a ellos, y de la enfermedad quedaron desnutridos... Saber como le prevenía, tal vez de desnutrición, como ellos son pepes, pepes los estaba yo criando...

La propia madre de Narciso, en principio tan proclive a las encarnaciones del modelo médico, abría la puerta a la explicación basada en el descuido materno, pero también a otras posibilidades en una búsqueda abierta hacia las causas cuando volvía a rememorar los acontecimientos: los efectos negativos de los remedios locales empleados, pero también lo "bastantes que son en la casa" y no llega a alcanzar, formas discursivas locales de apropiación del discurso de la planificación familiar, pero también otras posibilidades como la "falta de dulce" o que en ocasiones, simplemente, los niños se enferman. En esta parte del relato, la desnutrición entendida como un trastorno pierde protagonismo frente la desnutrición como síntoma, como consecuencia de otro mal, en este caso, "asientos". La nota presente es la multiplicidad de perspectivas:

O sea nosotros sabemos que tal vez que por algún mal que quedan con asientos los niños y les hacemos remedio y de eso quedan ellos así bien desnutridos pero es falta de alimentación se ponen ellos así, también es lo que pensamos nosotros que se arruinan ellos, por los remedios que usamos aquí, para hacerles remedio... hay días que amanece sin color de una vez, ipálido! No sabemos por qué, yo a veces pienso que ellos se quedan agotados porque en una semana ellos no beben café dulce, en eso quedan ellos, porque esta mi niña así fue, casi como más de tres semanas que no le compramos azúcar así se quedó él, le caen los asientos... a mi ver como de eso así quedó ella.

El trabajo de Good apunta hacia el sentido de estas múltiples perspectivas en un análisis más que interesante. Lejos de asumir cierto axioma de la antropología médica que apunta como las personas que tienen acceso a un sistema de atención médica plural no eligen entre formas alternativas, sino que usan todas las estrategias disponibles, a menudo todas a un tiempo, Good apuesta sobre la idea que "los relatos de enfermedad y la experiencia de curación que representan muy distintas y, a menudo contrapuestas, formas de composición de la enfermedad están presentes en los relatos porque mantienen las características de las subjuntividad y una apertura al 
cambio" (2003: 281), afirmando que las narraciones de casos trágicos o cerrados a la esperanza apenas manifestaban estas perspectivas múltiples. Lo que yo sostengo es que la presencia de esta multiplicidad de perspectivas para recrear lo subjuntivo no sólo se interseccionan con la experiencia y las expectativas de sanación de enfermos y familiares, sino que constituyen formas discursivas de prácticas reedificadoras de ordenes sociales y mundos morales. Los acontecimientos relatados seleccionan puntos de vista y acontecimientos, aportan puntos de vista alternativos, pero no lo hacen sólo como una forma de expresión de la acción social, sino que incorporan un esfuerzo performativo frente a la autoridad de las representaciones colectivas. Lo subjuntivo de los relatos se revela aquí como una herramienta poderosa de ofrecer verosimilitud al cambio, pero sobre todo a las renegociaciones de la culpa materna y las reelaboraciones culturales del daño y el sufrimiento.

Antes de asumir la retórica biomédica, los procesos de subjuntivización recrean un escenario donde la posibilidad de enfermar, aunque se hagan las cosas que se deben, es una posibilidad siempre acechante. En esa línea se incluye el relato de don Demetrio, un joven papá que había tenido ingresada a una de sus hijas en el dispensario Bethania; La enfermedad está siempre al acecho, vigilante, dominando, resultando más inteligente, a pesar de lo que pueda hacerse, aunque uno tenga "los espacios de la casa bien arreglados":

Pues por el momento yo no puedo decir nada, si pues. Pues yo no se de que trataría eso, porque legalmente allí siempre muchos niños han estado con diarrea, siempre, será por el clima o por el tiempo, no se sabe, ¿verdad? Pues muchos niños siempre han estado del mismo diarrea, han estado siempre dominando los niños; si como siempre en la aldeas, en la áreas, siempre hay personas que tienen a los niños bajo malcuido, tal vez los hogares que tienen mal aseados, así podrá decir, pero por el caso no se que pasaría eso, porque como dicen, la enfermedad siempre es más lista, aquella manera como dicen que pueda llegar a amenazar a los niños. Si pues, hay veces que aunque alguno pueda tener los sitios, los espacios de la casa bien arreglados, limpio, pero siempre la enfermedad nunca falla.

La enfermedad nunca falla. La enfermedad es más lista. Esa retórica de provisionalidad, el amparo a la expectativa siempre abierta de la desgracia es recurrente en los relatos y muy presente en la ideología local. Son de ese tipo de cosas que siempre han pasado, y que pueden pasar, dotando el futuro de una fragilidad que sirve como estrategia subjuntivizadora.

Las estrategias narrativas desde la experiencia de las cuidadoras parecen buscar, de esta forma, un tipo de "absolución cultural" sobre la responsabilidad que se les atribuye en las representaciones colectivas, dirimiendo culpas y daños, asumiendo con dificultad que el problema de la desnutrición sea un asunto de disponibilidad y responsables masculinos. Envueltos en la misma dinámica social donde se persigue otorgar sentido, los relatos construyen la historia, la dotan de una dirección y significado, dando paso a la alternancia, a finales e historias alternativas. En las tramas se insertan narraciones apegadas a conflictos familiares, a situaciones excepcionales y dramáticas que suponen quiebras con la cotidianidad, como los nuevos embarazos o las migraciones de los cabeza de familia a las fincas de café, y en ellos aparecen codificados las preocupaciones o diversos miedos. Las decisiones sobre acudir al hospital o pedir allí el alta voluntaria, las ayudas de la cooperación, los desenlaces fatales, la valo- 
ración de las comidas que alimentan o escenarios de vulnerabilidad como ser huérfanos de padre se cuelan en los relatos sobre la experiencia de la desnutrición. Este recorrido por los intersticios de la experiencia narrada lleva — a modo de ironía nada sorprendente- a la necesidad de apuntalar hacia estructuras y procesos en contextos más amplios: esto es, de lo íntimo y cercano de las despensas vacías, de la culpa y las dudas o de las negativas a los ingresos — "la guerra en el cuerpo" - a las relaciones asimétricas, a la ubicación en los márgenes, a la violencia que gobierna decisiones - "el cuerpo en la guerra". Bamboleos entre estructuras y experiencias que se interseccionan en un particular "espacio herido" (Ferrándiz 2007) de la región, donde se imbrican y construyen tales estrategias narrativas. Las definiciones indígenas sobre la "desnutrición" se construyen de esta manera en esta peculiar relación cultural entre relato, experiencia y contexto. Los esfuerzos del discurso modernizador de médicos y cooperantes por definir la desnutrición como un mero asunto de falta de alimentos y la solución en términos aritméticos de cuadrar balances calóricos choca aquí con los modos indígenas en que se construye el padecimiento, de la sickness (Young 1982: 270) y los límites culturales para la plasticidad narrativa de la experiencia.

Saltos etnográficos entre narración y experiencia, entre textos y culturas donde se mecen tonos particulares de desgracia, temores y miedos, conflictos o incertidumbres, aproximaciones a la representación sobre las nociones y experiencias del hambre y la desnutrición entre los ch'orti'. El acercamiento a las estrategias narrativas del padecimiento es todo eso de una vez. La desnutrición - y sus soluciones- es —o debería ser- un asunto mucho más denso que la retórica de los balances calóricos.

\section{BIBLIOGRAFÍA CITADA}

Bandahuer-Schoffmann, I. 1999. "El hambre en la memoria colectiva de la población Vienesa". Historia, Antropología y Fuentes Orales, 22: 113-130.

Brooks, P. 1984. Reading for the Plot. Design and Intention in Narrative. Nueva York: Vintage Books. Bruner, J. 1986. Actual Minds, Posible Worlds. Cambridge, Mass: Harvard University Press.

Edkins, J. 2000. Whose Hunger? Concepts of Famine, Practices of Aid. Minneapolis: University of Minnesota Press.

Ferrándiz, F. 2007. "Juventud en el respirador. Supervivencia y muerte en los barrios venezolanos", en J. A. Flores Martos y L. Abad, Etnografías de la muerte y las culturas en América Latina: 235251. Cuenca: Universidad de Castilla La Mancha.

Good, B. J. 2003. Medicina, racionalidad y experiencia. Una perspectiva antropológica. Barcelona: Bellaterra.

Iser, W. 1978. The Act of Reading. A Theory of Aesthetic Response. Baltimore: John Hopkins University Press.

Iser, W. 1989. "La estructura apelativa de los textos", en R. Warning (ed.), Estética de la recepción. Madrid: La Bolsa de la Medusa-Visor.

López García, J. 2002. "Exotismo y vivencia del hambre en Guatemala", en G. Diezt y B. Pérez (eds.), Procesos de Globalización y Localización en América Latina. Granada: Universidad de Granada.

López García, J. 2008. Catástrofes, pobreza y hambre en el oriente de Guatemala. Ciudad Real: Ediciones Puertollano.

Mariano Juárez, L. 2008. “Desnutrición, experiencia y apropiaciones Corporales. Tránsitos etnográficos para una cooperación al desarrollo Emocional", en J. López García, Catástrofes, pobreza y Hambre en el oriente de Guatemala: 115-164. Ciudad Real: Ediciones Puertollano.

Mariano Juárez, L. 2011. "Nostalgias del maíz y desnutrición contemporánea. Antropología del hambre en la región ch'orti' del oriente de Guatemala". Tesis Doctoral, Departamento Antropología Social, UNED. 
Mariano Juárez, L. 2012. "Maternidades e infancias "modernas" en discusión. Una aproximación a los diálogos - asimétricos - y la economía moral y política del desarrollo desde el oriente de Guatemala". Revista Chilena de Antropologia Visual, 19: 82-112.

Mariano Juárez, L. 2013. "El hambre en los espacios de la cultura. Visiones indígenas maya Ch'orti'”. AIBR, Revista de Antropología Iberoamericana, 8(2): 209-232.

Metz, E. B. 1995. Experiencing Conquest: The Political Economic Roots and Cultural Expresión of C'horti Maya Ethos. Tesis Doctoral, SUNY Albany.

Rowntree B. 1901. Poverty: a Study of Town Life. Londres: MacMillann.

Vernon, J. 2011. El hambre. Una historia moderna. Valencia: Universidad de Valencia.

Young, J. 1982. "The Anthropology of Illness and Sickness". Ann.Rev. Anthropology 11: 257:285.

Fecha de recepción: 28 de enero de 2015

Fecha de aceptación: 16 de marzo de 2015 